ORIGINAL ARTICLE

\title{
Systematic review of prevalence studies of autism spectrum disorders
}

J G Williams, J P T Higgins, C E G Brayne

Arch Dis Child 2006;91:8-15. doi: 10.1136/adc.2004.062083

See end of article for authors' affiliations

Correspondence to: Dr J G Williams,

Department of Public Health and Primary Care, University of Cambridge, Forvie Site, Robinson Way, Cambridge CB2 2SR, UK; i.g.williams.97@ cantab.net

Accepted

22 December 2004

Published Online First 29 April 2005

\begin{abstract}
Aim: To quantitatively examine the influence of study methodology and population characteristics on prevalence estimates of autism spectrum disorders.

Methods: Electronic databases and bibliographies were searched and identified papers evaluated against inclusion criteria. Two groups of studies estimated the prevalence of typical autism and all autism spectrum disorders (ASD). The extent of variation among studies and overall prevalence were estimated using metaanalysis. The influence of methodological factors and population characteristics on estimated prevalence was investigated using meta-regression and summarised as odds ratios (OR).

Results: Forty studies met inclusion criteria, of which 37 estimated the prevalence of typical autism, and 23 the prevalence of all ASD. A high degree of heterogeneity among studies was observed. The overall random effects estimate of prevalence across studies of typical autism was 7.1 per $10000195 \% \mathrm{Cl} 1.6$ to 30.6) and of all ASD was 20.0 per 10000 (95\% Cl 4.9 to 82.1). Diagnostic criteria used (ICD-10 or $\mathrm{DSM}-\mathrm{IV}$ versus other; $\mathrm{OR}=3.36,95 \% \mathrm{Cl} 2.07$ to 5.46$)$, age of the children screened $(\mathrm{OR}=0.91$ per year, $95 \% \mathrm{Cl} 0.83$ to 0.99 ), and study location (e.g. Japan versus North America; $\mathrm{OR}=3.60,95 \% \mathrm{Cl} 1.73$ to 7.46) were all significantly associated with prevalence of typical autism. Diagnostic criteria, age of the sample, and urban or rural location were associated with estimated prevalence of all ASD.

Conclusions: Sixty one per cent of the variation in prevalence estimates of typical autism was explained by these models. Diagnostic criteria used, age of children screened, and study location may be acting as proxies for other study characteristics and require further investigation.
\end{abstract}

$\mathrm{T}$ he prevalence of autistic disorder is now considered to be around 10 per 10000 , and the prevalence of pervasive developmental disorders, 27.5 per 10000 . These are derived from studies which have estimated prevalences of autistic disorder ranging from 0.7 to 72.6 per $10000 .{ }^{1}$ An increase in prevalence estimates has been observed over time, the reasons for which are not clear and may include: changes in study methodology; a genuine rise in autism risk factors; increase in services available, including diagnostic; increased awareness among educational and clinical professionals; and growing acceptance that autism can coexist with a range of other conditions. ${ }^{1-4}$

True variation in prevalence could generate aetiological hypotheses for autism and it is vital to understand what underpins the variation. Accurate estimates of the true prevalence are of value in planning diagnostic and intervention services.

Several narrative reviews have been conducted. This paper uses systematic and quantitative methods to examine reasons for variation in prevalence estimates. The aims are to assess the degree of variation among prevalence studies of autism, and to provide an overall summary of prevalence diversity taking into account among-study variance using metaanalysis. Aspects of study methodology and population characteristics are then examined using meta-regression to investigate their influence on prevalence estimates.

\section{METHODS}

\section{Literature searches}

Two databases, MEDLINE and EMBASE, were systematically searched by the first author (box 1). In addition, bibliographies of previous reviews ${ }^{156}$ were examined to identify published prevalence studies.

\section{Study selection}

Identified papers were examined against criteria for inclusion (box 2). The paper itself was examined if the abstract was

\section{Box 1: Search strategy for identifying} prevalence studies

MEDLINE (PubMed) (searched 13/04/04)

Years (1966-2004):

("Autistic-Disorder"/all subheadings [MeSH+] OR "Asperger-Syndrome"/all subheadings [MeSH] OR "Schizophrenia-Childhood"/all subheadings [MeSH] and (PY = 1966-1970) OR autis* (free text term)) AND ("Prevalence-"/all subheadings [MeSH] OR "CrossSectional-Studies"/all subheadings [MeSH] OR "MassScreening"/all subheadings [MeSH] OR "MultiphasicScreening"/all subheadings [MeSH]).

EMBASE (Excerpta Medica Database) (searched 13/04/04) (BIDS EMBASE, via Ovid, copyright 2003)

Years (1980-2004):

(expł autism/ OR exp infantile autism/OR exp Asperger syndrome/ OR autism.mp§ (as keyword) OR Asperger.mp (as keyword)) AND (exp prevalence/ OR exp mass screening/ OR exp screening/ OR cross-sectional.mp las keyword)) NOT (genetic screening/exp OR genetic screen.mp (as keyword).

†MeSH (Medical Subjects Headings), The National Library of Medicine controlled vocabulary for indexing articles in PubMed; †exp, explode term (search under all subheadings); $\S \mathrm{mp}$, uses the database thesaurus search term. 
insufficiently clear. Where there was more than one paper published on a particular study, the most recent was included in the review.

\section{Data extraction}

Methods and population characteristics reported across most studies were selected for data extraction. The first author extracted and coded the data. In studies using different diagnostic criteria, prevalence data based on the more recently published diagnostic criteria were extracted. The studies formed two groups: those that assessed the prevalence of classic autism, or autistic disorder, known here as "typical autism"; and those that assessed the prevalence of autism spectrum disorders (ASD) or all pervasive developmental disorders, known here as "all ASD". Assessments of risk of bias included reporting of refusal rates and the reliability of screen and assessment procedures.

\section{Analysis}

In the basic tables, crude prevalence estimates (number of cases/sample size) were presented, along with standard errors. For all meta-analyses and meta-regressions, prevalence estimates were transformed to $\operatorname{logits}\left(\log \frac{p}{1-p}\right)$ to improve their statistical properties. These were later backtransformed to prevalences and expressed as cases per 10000 people.

\section{Description of heterogeneity among studies and summary of prevalence}

Forest plots $^{8}$ were used to visualise the extent of heterogeneity among studies. Two statistical methods were used to quantify the variation. A standard test for heterogeneity examined the null hypothesis that the true prevalences are identical in every study. Since heterogeneity was expected a priori, this was supplemented with a measure of the degree of inconsistency across studies, $\mathrm{I}^{2} .{ }^{9} \mathrm{I}^{2}$ describes the proportion of variation in prevalence estimates that is due to genuine variation in prevalences rather than sampling error. It is expressed as a percentage, with $0 \%$ indicating consistency.

The random effects model assumes the study prevalences follow a normal distribution, allowing for among-study variation. ${ }^{10}$ The usual confidence interval for the mean in the random effects model does not take among-study variance into account, so is deceptively narrow when there is substantial variation across studies. Instead, a 95\% interval

\section{Box 2: Inclusion criteria}

(1) Primary research

(2) A geographically and temporally defined population

(3) Cross-sectional study or data, or first phase of a longitudinal study

(4) Defined diagnostic criteria stated for autism or autism spectrum disorder

(5) Includes individuals under 18 years old

(6) Initial selection in a wide range of children in the general population, or in a clinical setting

(7) Final identification of cases based on clinical or other diagnostic assessment of selected children

(8) Published in English, or with detailed summaries in English

(9) Peer reviewed paper or conference presentation

(10) Includes prevalence data (criteria adapted from Wing ${ }^{7}$ ) for the true prevalence was calculated as the mean of $\operatorname{logits} \pm 1.96 \tau$, where $\tau$ is the among-study standard deviation. ${ }^{11}$

Investigation of sources of heterogeneity

The potential influence of covariates on the prevalence estimates was investigated using a random effects regression model, thus taking account of among-study variance, using the metareg command in STATA. ${ }^{12}$ The regression coefficients represent log odds ratios, which are presented as odds ratios with $95 \%$ confidence intervals.

A multivariate meta-regression model was constructed to investigate which covariates were associated with prevalence estimates if there was adjustment for other study covariates. The fit of each model was assessed using the percentage of among-study variance explained $\left(\left(1-\left(\tau^{2}\right.\right.\right.$ in $\operatorname{model} / \tau^{2}$ in model with no covariates $)(\times 100)$, together with a significance test for each introduced variable $(\mathrm{T}=$ coefficient/SE, related to the $\mathrm{t}$-distribution). The models were constructed using a forward stepwise procedure as described in the results section. For each model a maximum number of covariates was set at $\mathrm{n} / \mathrm{1} 0$ where $\mathrm{n}$ was the number of studies, following standard recommendations for model size relative to sample size. ${ }^{13}$

\section{RESULTS}

\section{Studies identified}

Literature searches identified 670 papers (including duplicates). After exclusion through comparison of titles and abstracts against inclusion criteria, 77 papers were identified for detailed examination. Thirty seven papers were excluded, including ten on the basis of inclusion criterion 2 (box 2), ten on the basis of criterion 4, nine on the basis of 6 , and one on the basis of 7. In addition, four papers did not have detailed English summaries, one was not peer reviewed, and two were untraceable. Of these seven potentially eligible studies, four were conducted in Japan, one in the USA, one in France, and one in Sweden.

Forty papers met inclusion criteria, of which 37 gave estimates for typical autism and 23 for all ASD (table 1). The study sample sizes ranged from 826 to 4590333 (median $=48705)$. Only $17(40 \%)$ studies reported the refusal rate at the screen phase of the study, and 13 (33\%) at the assessment stage. Six (15\%) studies reported investigating the reliability of their screen method, and $11(26 \%)$ studies stated that the inter-rater reliability for the diagnostic assessment had been investigated. Many studies did not report refusal rates and reliability, so these covariates could not be included in further analyses.

\section{Description of heterogeneity among studies and summary of prevalence}

There was clearly wide variation in the prevalence estimates of typical autism (fig 1) and an increase in prevalence estimates over time. The $\mathrm{Q}$ statistic was very large $\left(\mathrm{Q}=1947.6, \mathrm{df}=36, \mathrm{p}<0.00 \mathrm{l} ; \mathrm{I}^{2}=98.2 \%\right)$, showing that there was a great deal of variation among the studies. There was also a high degree of heterogeneity among estimates of all ASD (fig 2) $\left(\mathrm{Q}=1577.7, \mathrm{df}=22, \mathrm{p}<0.001 ; \mathrm{I}^{2}=98.6 \%\right)$.

The back-transformed mean of the random effects distribution for studies of typical autism was 7.1 per 10000 (95\% interval for true prevalences: 1.6 to 30.6 ) and for studies of all ASD was 20.0 per 10000 (95\% interval for true prevalences: 4.9 to 82.1 ).

\section{Investigation of sources of heterogeneity}

Two studies were excluded from the regression analyses: either the published paper was not available, ${ }^{16}$ or insufficient 


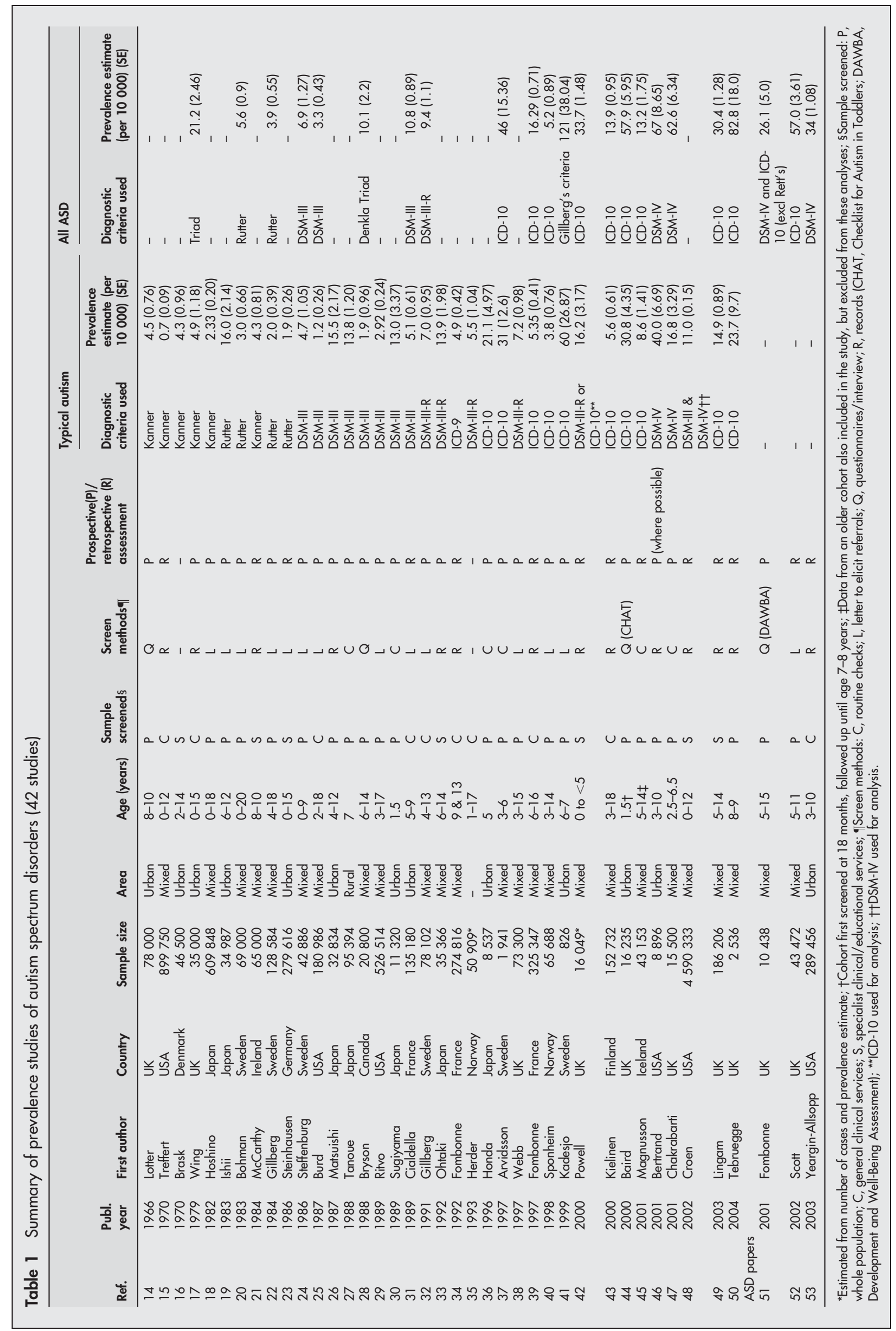


Study

Lotter, 1966

Treffert, 1970

Brask, 1970

Wing, 1979

Hoshino, 1982

Ishii, 1983

Bohman, 1983

McCarthy, 1984

Gillberg, 1984

Steinhausen, 1986

Steffenburg, 1986

Burd, 1987

Matsuishi, 1987

Tanove, 1988

Bryson, 1988

Ritvo, 1989

Sugiyama, 1989

Ciadella, 1989

Gillberg, 1991

Ohtaki, 1992

Fombonne, 1992

Herder, 1993

Honda, 1996

Arvidsson, 1997

Webb, 1997

Fombonne, 1997

Sponheim, 1998

Kadesjo, 1999

Powell, 2000

Kielinen, 2000

Baird, 2000

Magnusson, 2001

Bertrand, 2001

Chakrabarti, 2001

Croen, 2002

Lingam, 2003

Tebruegge, 2004
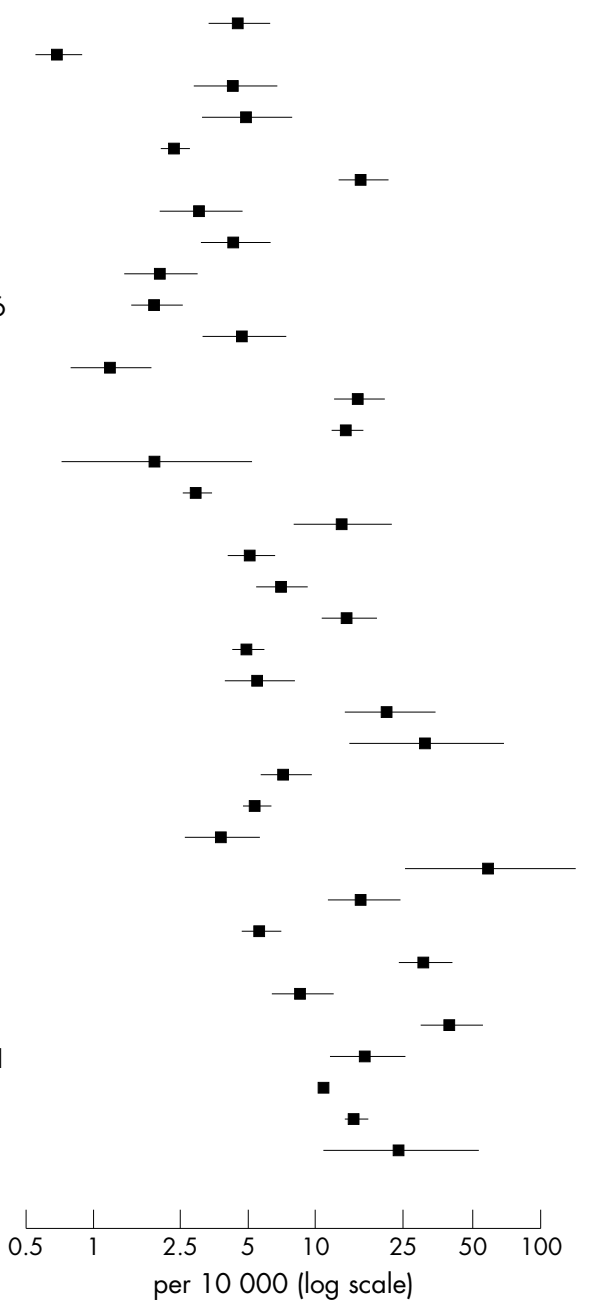

Figure 1 Forest plot of prevalence estimates and $95 \%$ confidence intervals from studies of typical autism, log transformed $(n=37)$.

information on study methodology was included in the English abstract of a Swedish paper. ${ }^{35}$

\section{Studies of typical autism}

The associations between study covariates and prevalence estimates of typical autism from univariate meta-regression analyses are shown in table 2 . Taking account of the age of the children, for example, explained $23 \%$ of the amongstudies variance.

Diagnostic criteria and decade of publication were the covariates that explained the most variance among studies in the univariate analyses. These two covariates are collinear and it was not possible to include both in a multivariate model. The diagnostic criteria used were entered first into the multivariate model since this was considered to be more directly related to variation in prevalence estimates than decade of publication, which is a proxy for all time varying covariates. The binary categorisation of diagnostic criteria was used, as it was not possible to use multiple categories of diagnostic criteria in a multivariate analysis with so few studies. Age of the children screened also explained much among-study variance, and was entered next into the model.

Models with three covariates were constructed which included age, diagnostic criteria, and each remaining covariate in turn. Screening method used, and whether the
Study

Wing, 1979

Bohman, 1983

Gillberg, 1984

Steffenburg, 1986

Burd, 1987

Bryson, 1988

Cialdella, 1989

Gillberg, 1991

Arvidsson, 1997

Fombonne, 1997

Sponheim, 1998

Kadesio, 1999

Powell, 2000

Kielinen, 2000

Baird, 2000

Magnusson, 2001

Chakrabarti, 2001

Bertrand, 2001

Fombonne, 2001

Scott, 2002

Lingam, 2003

Yeargin-Allsopp, 2003

Tebruegge, 2004

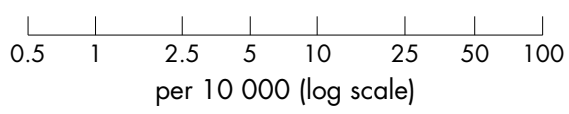

Figure 2 Forest plot of prevalence estimates and $95 \%$ confidence intervals from studies of all ASD, log transformed $(n=23)$.

study was on a population or clinic based sample, were not significantly associated with prevalence. Urban location gave rise to higher prevalence estimates than studies carried out in rural or mixed locations $(\mathrm{OR}=1.90,95 \%$ CI 1.10 to 3.25 ; among-study variance explained $=53 \%$ ). Studies that drew on records of previous diagnostic assessments resulted in lower prevalence estimates than those which included a prospective diagnostic assessment $(\mathrm{OR}=0.57,95 \% \mathrm{CI} 0.33$ to 0.96 ; variance explained $=53 \%$ ). Including region of study provided the model that explained the most among-study variance (variance explained $=61 \%$ ) (table 3 ). In this final model, using ICD-10 or DSM-IV led to prevalence estimates three times those using other diagnostic criteria. The odds ratio for age was 0.91 ( $95 \%$ CI 0.83 to 0.99 ), showing that an increase of one year in the age of the children screened led to a significant reduction in prevalence estimates. For example, when the odds ratio is taken to approximate a relative risk, if prevalence was estimated to be 10 per 10000 in a sample of 5 year olds, it would be expected to be around 9.1 per 10000 in a sample of 6 year olds. Studies in Japan gave rise to prevalence estimates that were 3.6 times those in North America.

\section{Studies of all ASD}

The associations between study covariates and prevalence estimates of all ASD from univariate meta-regression analyses are shown in table 4 . Only three covariates were significantly associated with the prevalence estimates: age of the children screened, urban or rural study location, and the diagnostic criteria used. The screen method used was of borderline significance. Of these, diagnostic criteria explained most among-study variance, and was therefore included in the multivariate analyses. Each of the other covariates was introduced into the model in turn to form models with two covariates. As in the analyses of studies of typical autism, as decade and diagnostic criteria were collinear, only the covariate for diagnostic criteria was included in further analyses. When adjusting for diagnostic criteria, the only 
Table 2 Results of meta-regression of studies of typical autism, univariate analyses $(n=35)$

\begin{tabular}{|c|c|c|c|c|c|c|c|}
\hline Covariate & $\begin{array}{l}\text { Categories of covariate } \\
\text { (first listed used as baseline) }\end{array}$ & No. studies & Odds ratio & $95 \% \mathrm{Cl}$ (odds ratio) & $p$ value & $\tau^{2}$ & $\begin{array}{l}\text { Variance } \\
\text { explained (\%) }\end{array}$ \\
\hline No covariates & & 35 & - & - & - & 0.98 & - \\
\hline Age & $\begin{array}{l}\text { Mid-point of age range } \\
\text { (continuous variable) }\end{array}$ & 35 & 0.84 & 0.75 to 0.93 & 0.002 & 0.75 & 23 \\
\hline \multirow[t]{4}{*}{ Decade } & 1960 s and 1970 s & 3 & 1.00 & - & - & 0.58 & 41 \\
\hline & $1980 s$ & 14 & 1.80 & 0.68 to 4.81 & 0.24 & & \\
\hline & $1990 \mathrm{~s}$ & 9 & 4.26 & 1.52 to 11.94 & 0.006 & & \\
\hline & $2000 s$ & 9 & 6.42 & 2.29 to 17.99 & $<0.001$ & & \\
\hline \multirow[t]{3}{*}{ Region* } & N. America & 6 & 1.00 & - & - & 0.85 & 13 \\
\hline & Japan & 7 & 3.19 & 1.14 to 8.94 & 0.03 & & \\
\hline & Europe and Scandinavia & 22 & 2.05 & 0.87 to 4.85 & 0.10 & & \\
\hline \multirow[t]{2}{*}{ Area } & Rural/mixed & 24 & 1.00 & - & - & 0.86 & 12 \\
\hline & Urban & 11 & 2.10 & 1.07 to 4.14 & 0.03 & & \\
\hline \multirow{2}{*}{ Sample screened $\dagger$} & Population based & 21 & 1.00 & - & - & 0.88 & 10 \\
\hline & Clinic based & 14 & 0.54 & 0.28 to 1.03 & 0.06 & & \\
\hline \multirow[t]{4}{*}{ Screen method } & Routine checks & 6 & 1.00 & - & - & 0.77 & 21 \\
\hline & Letter for referrals & 13 & 0.28 & 0.12 to 0.68 & 0.005 & & \\
\hline & Questionnaires & 3 & 0.45 & 0.13 to 1.62 & 0.22 & & \\
\hline & Records & 13 & 0.53 & 0.22 to 1.27 & 0.16 & & \\
\hline \multirow[t]{2}{*}{ Assessment } & Prospective & 23 & 1.00 & - & - & 0.95 & 3 \\
\hline & Retrospective & 12 & 0.73 & 0.37 to 1.46 & 0.38 & & \\
\hline \multirow[t]{2}{*}{ Diagnostic criterion 1} & Not ICD-10 or DSM-IV & 21 & 1.00 & - & - & 0.64 & 35 \\
\hline & ICD-10 or DSM-IV & 14 & 3.32 & 1.89 to 5.81 & $<0.001$ & & \\
\hline \multirow{7}{*}{ Diagnostic criterion 2} & Kanner & 5 & 1.00 & - & - & 0.54 & 45 \\
\hline & Rutter & 4 & 1.38 & 0.51 to 3.71 & 0.53 & & \\
\hline & DSM-III & 8 & 1.95 & 0.84 to 4.57 & 0.12 & & \\
\hline & DSM-III-R & 3 & 3.29 & 1.13 to 9.58 & 0.03 & & \\
\hline & ICD-9 & 1 & 1.82 & 0.37 to 8.85 & 0.46 & & \\
\hline & ICD-10 & 11 & 5.10 & 2.29 to 11.47 & $<0.001$ & & \\
\hline & DSM-IV & 3 & 7.17 & 2.46 to 20.91 & $<0.001$ & & \\
\hline
\end{tabular}

${ }^{*}$ Region = North America: USA and Canada; Japan; Europe (UK, France, Germany, Ireland) and Scandinavia (Denmark, Sweden, Norway, Finland, Iceland). †Sample screened $=$ whole population versus clinic based (general clinical services and clinic specialist services).

\begin{tabular}{|c|c|c|c|c|}
\hline Covariate & & Odds ratio & $95 \% \mathrm{Cl}$ (odds ratio) & $p$ value \\
\hline \multirow[t]{2}{*}{ Diagnostic criteria } & Not ICD-10 or DSM-IV & 1.00 & - & - \\
\hline & ICD-10 or DSM-IV & 3.36 & 2.07 to 5.46 & $<0.001$ \\
\hline Age (years) & & 0.91 & 0.83 to 0.99 & 0.03 \\
\hline \multirow{3}{*}{ Region } & North America & 1.00 & - & - \\
\hline & Japan & 3.60 & 1.73 to 7.46 & 0.001 \\
\hline & Europe and Scandinavia & 1.67 & 0.92 to 3.02 & 0.09 \\
\hline \multicolumn{2}{|l|}{ Intercept } & $5.15 \times 10^{-4}$ & $2.06 \times 10^{-4}$ to $1.29 \times 10^{-3}$ & $<0.001$ \\
\hline
\end{tabular}

covariates that were significantly associated with the prevalence estimates were the age of the children screened (variance explained $=50 \%$ ) and urban or rural study location (variance explained $=53 \%$ ). Both these models are presented (table 5). Using ICD-10 or DSM-IV gave rise to prevalence estimates that were over twice those in studies using other diagnostic criteria. When including age in the model, an increase in the age of the sample by one year was associated with a fall in prevalence by a factor of approximately 0.85 , taking the odds ratio as an approximation of a relative risk. Alternatively, when including study location, studies in urban areas gave rise to prevalence estimates over 2.5 times those in rural or mixed urban and rural areas.

\section{DISCUSSION}

\section{Main findings}

As expected, a large amount of variation in prevalence across studies was found by graphical representation of estimates and by indices of heterogeneity. Despite this wide variation, pooled estimates are useful to indicate the public health burden of the disorder. The study variation is reflected in the very large intervals on the summaries of overall prevalence. The estimates of around 7.1 per 10000 for typical autism, and 20.0 per 10000 for all ASD are slightly lower than those estimated previously at $8.7-10.0$ per 10000 and 27.5 per 10000 respectively. ${ }^{13}$

The covariate most strongly associated with prevalence estimates for typical autism and all ASD was the diagnostic criteria used. This association has been recognised previously. ${ }^{2-4}$ The time variation in prevalence is so closely linked to changes in diagnostic criteria, the two could not be examined separately. Furthermore, it was not possible to account entirely for the effect of the diagnostic criteria on the prevalence estimates as the ICD-10 and DSM-IV diagnostic schema leave some scope for variation in their interpretation and application.

The age of the children screened was strongly associated with the prevalence estimates. Manifestations of ASD may be more obvious in younger children. Alternatively, some screening methods may be more sensitive for younger children. Methods of screening were found to be significantly associated with the prevalence estimates in the univariate analyses of typical autism, but not after adjusting for the age of the children screened.

The multivariate model that explained most among-study variance in studies of typical autism included the region 
Table 4 Results of meta-regression of studies of all autism spectrum disorders, univariate analyses $(n=23)$

\begin{tabular}{|c|c|c|c|c|c|c|c|}
\hline Covariate* $^{*}$ & $\begin{array}{l}\text { Categories of covariate } \\
\text { (first listed used as baseline) }\end{array}$ & No. studies & Odds ratio & $95 \% \mathrm{Cl}$ (odds ratio) & $p$ value & $\tau^{2}$ & $\begin{array}{l}\text { Variance } \\
\text { explained (\%) }\end{array}$ \\
\hline No covariates & & 23 & & & & 1.01 & \\
\hline Age & $\begin{array}{l}\text { Mid-point of age range } \\
\text { (continuous variable) }\end{array}$ & 23 & 0.82 & 0.72 to 0.94 & 0.005 & 0.74 & 27 \\
\hline \multirow[t]{4}{*}{ Decade } & 1960 s and 1970s & 1 & 1.00 & - & - & 0.43 & 57 \\
\hline & 1980 s & 6 & 0.29 & 0.07 to 1.19 & 0.09 & & \\
\hline & 1990 s & 5 & 0.93 & 0.22 to 3.94 & 0.92 & & \\
\hline & $2000 \mathrm{~s}$ & 11 & 1.75 & 0.44 to 6.89 & 0.42 & & \\
\hline \multirow[t]{4}{*}{ Region } & N. America & 4 & 1.00 & - & - & 0.77 & 24 \\
\hline & Japan & 0 & - & - & - & - & - \\
\hline & Europe & 10 & 1.99 & 0.70 to 5.58 & 0.19 & & \\
\hline & Scandinavia & 9 & 0.72 & 0.25 to 2.05 & 0.54 & & \\
\hline \multirow[t]{2}{*}{ Area } & Rural/mixed & 17 & 1.00 & - & - & 0.86 & 15 \\
\hline & Urban & 6 & 2.44 & 1.02 to 5.81 & 0.05 & & \\
\hline \multirow[t]{2}{*}{ Sample screened } & Population based & 14 & 1.00 & - & - & 0.97 & 4 \\
\hline & Clinic based & 9 & 0.66 & 0.29 to 1.54 & 0.34 & & \\
\hline \multirow[t]{4}{*}{ Screen method } & Routine checks & 3 & 1.00 & - & - & 0.72 & 29 \\
\hline & Letter for referrals & 9 & 0.31 & 0.10 to 0.98 & 0.05 & & \\
\hline & Questionnaires & 3 & 0.76 & 0.19 to 3.03 & 0.69 & & \\
\hline & Records & 8 & 0.93 & 0.30 to 2.97 & 0.91 & & \\
\hline \multirow[t]{2}{*}{ Assessment } & Prospective & 14 & 1.00 & - & - & 0.96 & 5 \\
\hline & Retrospective & 9 & 1.52 & 0.66 to 3.49 & 0.32 & & \\
\hline \multirow[t]{2}{*}{ Diagnostic criterion 1} & Not ICD-10 or DSM-IV & 9 & 1.00 & - & & 0.69 & 32 \\
\hline & ICD-10 or DSM-IV & 14 & 3.08 & 1.52 to 6.25 & 0.002 & & \\
\hline
\end{tabular}

Table 5 Two multivariate meta-regression models for studies of all autism spectrum disorders $(n=23)$

\begin{tabular}{|c|c|c|c|c|}
\hline Covariate & & Odds ratio & $95 \% \mathrm{Cl}$ (odds ratio) & $p$ value \\
\hline \multicolumn{5}{|c|}{ Model 1 -including age } \\
\hline \multirow[t]{2}{*}{ Diagnostic criteria } & Not ICD-10 or DSM-IV & 1.00 & - & - \\
\hline & ICD-10 or DSM-IV & 2.61 & 1.40 to 4.85 & 0.003 \\
\hline Age (years) & 0.85 & 0.85 & 0.76 to 0.96 & 0.006 \\
\hline Intercept & $1.45 \times 10^{-3}$ & $1.45 \times 10^{-3}$ & $3.25 \times 10^{-4}$ to $6.45 \times 10^{-3}$ & $<0.001$ \\
\hline \multicolumn{5}{|c|}{ Model 2-including study area } \\
\hline \multirow[t]{2}{*}{ Diagnostic criteria } & Not ICD-10 or DSM-IV & 1.00 & - & - \\
\hline & ICD-10 or DSM-IV & 3.48 & 1.92 to 6.33 & $<0.001$ \\
\hline \multirow[t]{2}{*}{ Area } & Rural/mixed & 1.00 & - & - \\
\hline & Urban & 2.85 & 1.47 to 5.53 & 0.002 \\
\hline Intercept & & $2.03 \times 10^{-4}$ & $7.15 \times 10^{-5}$ to $5.73 \times 10^{-4}$ & $<0.001$ \\
\hline
\end{tabular}

studied, with studies from Japan having significantly higher estimates than North American studies. This could be due to other study factors. For example, a higher proportion of the Japanese studies were from urban areas (4/7 (57\%) studies) compared to those in North America (1/6 (17\%) studies). All the Japanese studies used prospective diagnostic assessments, and all but one drew on whole population rather than clinical samples. Due to the imposed limit of three covariates in the model, it was not possible to adjust for further potential effect modifiers. Countries differ in their diagnostic practice both in their theoretical background and their training procedures for healthcare workers. This may, in part, account for between-region variation in prevalence.

In an alternative model for typical autism, when adjusting for age and diagnostic criteria, studies including prospective diagnostic assessments gave rise to higher prevalence estimates than those using retrospective records. This may be linked to the use of different diagnostic methodology at different times. Alternatively, an assessor taking part in prospective research studies might observe children more closely for symptoms of ASD.

When adjusting for diagnostic criteria, urban location was also observed to be associated with higher prevalence estimates for both typical autism and all ASD. If the screen method relied on records, these may have been more complete in urban locations. If the screen method used referrals from clinicians, it is possible that a higher proportion of children were known to services in urban locations. There may have been different diagnostic practices in urban locations where staff were more likely to be employed at specialist healthcare centres than in rural locations. It is easier to access the population in urban locations, and response rates may have been higher, but data on response were too limited to investigate this.

Limitations and recommendations for future research Publication bias was not investigated in this review, as funnel plots were not considered appropriate due to the large degree of variation across studies. It is unlikely that the set of papers published is biased with respect to prevalence reported. However, it is possible that some studies were not identified in the searches if they were not published in mainstream journals. There may have been some time lag bias, with smaller studies, or studies with unremarkable results, coming through to publication slower than larger studies.

Of the papers identified for detailed examination, five potentially eligible studies were excluded as they did not have a detailed English summary or were not peer reviewed. There 
is no reason to suspect that the lack of availability of data from these studies is a direct consequence of the prevalences they might have observed.

The choice of coding of the covariates may have affected the model, such as using the midpoint of the age range or grouping diverse diagnostic criteria. Furthermore, it was only possible to assess the impact of reported covariates, or easily quantifiable covariates. Qualitative influences on prevalence such as awareness of autism in each population could not be included. As more studies are published, it may be possible to include new covariates or more precise coding of existing covariates in such a model. It would be valuable to have even more thorough recording of study characteristics in future studies to facilitate meta-analyses of studies.

It is unlikely that it would ever be possible to measure and record all potentially important covariates. An alternative approach to investigating trends in prevalence, through ongoing monitoring of defined school aged populations using standard methodology, has been recommended. ${ }^{1}$ This would enable researchers to investigate changes in prevalence over time, and geographical variations while controlling for study methodology.

\section{Conclusions}

This review has contributed to explaining some of the influences on variation among prevalence estimates. Over half of the variation among study estimates can be explained by the age of the children screened, the diagnostic criteria used, and the country studied. Other important factors were whether the study was in a rural or urban location and whether cases were assessed prospectively or retrospectively. The impact of these identified factors on prevalence estimates should now be further investigated as they may be acting as proxies for other influences on prevalence. For example, the effect of geographical location on prevalence may be due to the services available, or variation in awareness of the disorder. By taking this quantitative approach, this review has shown that using meta-analytic techniques can be a valuable additional tool in deepening our understanding of the influences of study and population characteristics on variation in prevalence estimates in autism spectrum disorders.

\section{ACKNOWLEDGEMENTS}

This work forms part of a PhD thesis entitled "Screening for autism spectrum disorders" (University of Cambridge, 2003). Jo Williams (née Johnson) held an MRC studentship, and subsequently received funding from the Shirley Foundation. We wish to thank Prof Patrick Bolton and Prof Simon Baron-Cohen for their comments on an earlier draft of this paper.

\footnotetext{
Authors' affiliations

J G Williams, C E G Brayne, Department of Public Health and Primary Care, University of Cambridge, UK

J P T Higgins, MRC Biostatistics Unit, Cambridge, UK and Public Health Genetics Unit, University of Cambridge, UK

Competing interests: none declared

\section{REFERENCES}

1 Fombonne E. Epidemiological surveys of autism and other pervasive developmental disorders: an update. J Autism Dev Disord 2003;33:365-82.

2 Wing L, Potter D. The epidemiology of autistic spectrum disorders: is the prevalence rising? Mental Retardation and Developmental Disabilities Research Review 2002;8:151-61.

3 Fombonne E. Epidemiological trends in rates of autism. Mol Psychiatry 2002;7(suppl 2):S4-6

4 Charman T. The prevalence of autism spectrum disorders. Recent evidence and future challenges. Eur Child Adolesc Psychiatry 2002;11:249-56.

5 Fombonne E. The epidemiology of autism: a review. Psychol Med 1999;29:769-86.
}

6 Gillberg C, Wing L. Autism: not an extremely rare disorder. Acta Psychiatr Scand 1999;99:399-406

7 Wing L. The definition and prevalence of autism: a review. European Child and Adolescent Psychiatry 1993;2:61-74.

8 Lewis S, Clarke M. Forest plots: trying to see the wood and the trees. BMJ 2001;322:1479-80

9 Higgins JP, Thompson SG, Deeks JJ, et al. Measuring inconsistency in metaanalyses. BMJ 2003;327:557-60.

10 Whitehead A, Whitehead J. A general parametric approach to the metaanalysis of randomized clinical trials. Stat Med 1991;10:1665-77.

11 Goodman SN. Meta-analysis and evidence. Control Clin Trials 1989; 10:188-204.

12 Sharp S. Meta-analysis regression. Stata Technical Bulletin Reprints 2003;7(STB42): 148-55

13 Altman D. Practical statistics for medical research. London: Chapman \& Hall, 1991:349.

14 Lotter V. Epidemiology of autistic conditions in young children. Social Psychiatry 1966;1:124-37.

15 Treffert DA. Epidemiology of infantile autism. Arch Gen Psychiatry 1970;22:431-8.

16 Brask BH. A prevalence investigation of childhood psychoses. Nordic symposium on the care of psychotic children. Oslo: Barnepsychiatrist Forening, Universitetsforlagets Trykningssentral, 1970.

17 Wing L, Gould J. Severe impairments of social interaction and associated abnormalities in children: epidemiology and classification. J Autism Dev Disord 1979;9:11-29.

18 Hoshino $Y$, Kumashiro $H$, Yashima Y, et al. The epidemiological study of autism in Fukushima-ken. Folia Psychiatr Neurol Jpn 1982;36:115-24.

19 Ishii T, Takahashi O. The epidemiology of autistic children in Toyota, Japan: prevalence. Japanese Journal of Child and Adolescent Psychiatry 1983;24:311-21.

20 Bohman M, Bohman IL, Bjorck PO, et al. Childhood psychosis in a northern Swedish county: some preliminary findings from an epidemiological survey. In: Schmidt M, Schmidt R, eds. Epidemiological approaches in child psychiatry. Stuttgart: George Thieme Verlag, 1983:164-73.

21 McCarthy P, Fitzgerald M, Smith MA. Prevalence of childhood autism in Ireland. Ir Med J 1984;77:129-30.

22 Gillberg C. Infantile autism and other childhood psychoses in a Swedish urban region. Epidemiological aspects. J Child Psychol Psychiatry 1984;25:35-43.

23 Steinhausen HC, Gobel D, Breinlinger M, et al. A community survey of infantile autism. J Am Acad Child Psychiatry 1986;25:186-9.

24 Steffenburg S, Gillberg C. Autism and autistic-like conditions in Swedish rural and urban areas: a population study. Br J Psychiatry 1986;149:81-7.

25 Burd L, Fisher W, Kerbeshian J. A prevalence study of pervasive developmental disorders in North Dakota. J Am Acad Child Adolesc Psychiatry 1987;26:700-3.

26 Matsuishi T, Shiotsuki Y, Yoshimura K, et al. High prevalence of infantile autism in Kurume City, Japan. J Child' Neurol 1987;2:268-71.

27 Tanoue $Y$, Oda S, Asano F, et al. Epidemiology of infantile autism in southern Ibaraki, Japan: differences in prevalence in birth cohorts. J Autism Dev Disord 1988; 18:155-66.

28 Bryson SE, Clark BS, Smith IM. First report of a Canadian epidemiological study of autistic syndromes. J Child Psychol Psychiatry 1988;29:433-45.

29 Ritvo ER, Freeman BJ, Pingree C, et al. The UCLA-University of Utah epidemiologic survey of autism: prevalence. Am J Psychiatry 1989;146:194-9.

30 Sugiyama T, Abe T. The prevalence of autism in Nagoya, Japan: a total population study. J Autism Dev Disord 1989;19:87-96.

31 Cialdella P, Mamelle N. An epidemiological study of infantile autism in a French department (Rhone): a research note. J Child Psychol Psychiatry 1989;30:165-75

32 Gillberg C, Steffenburg S, Schaumann $\mathrm{H}$. Is autism more common now than ten years ago? Br J Psychiatry 1991;158:403-9.

33 Ohtaki E, Kawano Y, Urabe F, et al. The prevalence of Rett syndrome and infantile autism in Chikugo District, the southwestern area of Fukuoka prefecture, Japan [letter]. J Autism Dev Disord 1992;22:452-4.

34 Fombonne $\mathbf{E}$, du Mazaubrun C. Prevalence of infantile autism in four French regions. Soc Psychiatry Psychiatr Epidemiol 1992;27:203-10.

35 Herder GA. [Infantile autism among children in the county of Nordland. Prevalence and etiology]. Tidsskr Nor Laegeforen 1993;1 13:2247-9.

36 Honda H, Shimizu Y, Misumi K, et al. Cumulative incidence and prevalence of childhood autism in children in Japan. Br J Psychiatry 1996;169:228-35.

37 Arvidsson T, Danielsson B, Forsberg P, et al. Autism in 3-6-year-old children in a suburb of Goteborg, Sweden. Autism 1997;1:163-73.

38 Webb EV, Lobo S, Hervas A, et al. The changing prevalence of autistic disorder in a Welsh health district. Dev Med Child Neurol 1997;39:150-2.

39 Fombonne E, du Mazaubrun C, Cans C, et al. Autism and associated medical disorders in a French epidemiological survey. J Am Acad Child Adolesc Psychiatry 1997;36:1561-9.

40 Sponheim E, Skjeldal O. Autism and related disorders: epidemiological findings in a Norwegian study using ICD-10 diagnostic criteria. J Autism Dev Disord 1998;28:217-27.

41 Kadesjo B, Gillberg C, Hagberg B. Brief report: autism and Asperger syndrome in seven-year-old children: a total population study. J Autism Dev Disord 1999:29:327-31.

42 Powell JE, Edwards A, Edwards $M$, et al. Changes in the incidence of childhood autism and other autistic spectrum disorders in preschool children from two areas of the West Midlands, UK. Dev Med Child Neurol 2000;42:624-8. 
43 Kielinen M, Linna SL, Moilanen I. Autism in Northern Finland. Eur Child Adolesc Psychiatry 2000;9:162-7.

44 Baird G, Charman T, Baron-Cohen S, et al. A screening instrument for autism at 18 months of age: a 6-year follow- up study. J Am Acad Child Adolesc Psychiatry 2000;39:694-702.

45 Magnusson P, Saemundsen E. Prevalence of autism in Iceland. J Autism Dev Disord 2001;31:153-63

46 Bertrand J, Mars A, Boyle C, et al. Prevalence of autism in a United States population: the Brick Township, New Jersey, investigation. Pediatrics 2001; 108:1155-61.

47 Chakrabarti S, Fombonne E. Pervasive developmental disorders in preschool children. JAMA 2001;285:3093-9.

48 Croen LA, Grether JK, Hoogstrate J, et al. The changing prevalence of autism in California. J Autism Dev Disord 2002;32:207-15.
49 Lingam R, Simmons A, Andrews N, et al. Prevalence of autism and parentally reported triggers in a north east London population. Arch Dis Child 2003;88:666-70

50 Tebruegge M, Nandini V, Ritchie J. Does routine child health surveillance contribute to the early detection of children with pervasive developmental disorders? An epidemiological study in Kent, U.K. BMC Pediatr 2004;4:4.

51 Fombonne E, Simmons H, Ford T, et al. Prevalence of pervasive developmental disorders in the British nationwide survey of child mental health. J Am Acad Child Adolesc Psychiatry 2001:40:820-7.

52 Scott F, Baron-Cohen S, Bolton P, et al. Brief report: prevalence of autism spectrum conditions in children aged 5-11 years in Cambridgeshire, UK. Autism 2002;6:231-7

53 Yeargin-Allsopp M, Rice C, Karapurkar T, et al. Prevalence of autism in a US metropolitan area. JAMA 2003;289:49-55.

\section{Clinical Evidence-Call for contributors}

Clinical Evidence is a regularly updated evidence-based journal available worldwide both as a paper version and on the internet. Clinical Evidence needs to recruit a number of new contributors. Contributors are healthcare professionals or epidemiologists with experience in evidence-based medicine and the ability to write in a concise and structured way.

Areas for which we are currently seeking contributors:

- Pregnancy and childbirth

- Endocrine disorders

- Palliative care

- Tropical diseases

We are also looking for contributors for existing topics. For full details on what these topics are please visit www.clinicalevidence.com/ceweb/contribute/index.jsp

However, we are always looking for others, so do not let this list discourage you.

Being a contributor involves:

- Selecting from a validated, screened search (performed by in-house Information Specialists) epidemiologically sound studies for inclusion.

- Documenting your decisions about which studies to include on an inclusion and exclusion form, which we keep on file.

- Writing the text to a highly structured template (about 1500-3000 words), using evidence from the final studies chosen, within 8-10 weeks of receiving the literature search.

- Working with Clinical Evidence editors to ensure that the final text meets epidemiological and style standards.

- Updating the text every 12 months using any new, sound evidence that becomes available. The Clinical Evidence in-house team will conduct the searches for contributors; your task is simply to filter out high quality studies and incorporate them in the existing text.

If you would like to become a contributor for Clinical Evidence or require more information about what this involves please send your contact details and a copy of your CV, clearly stating the clinical area you are interested in, to CECommissioning@bmigroup.com.

\section{Call for peer reviewers}

Clinical Evidence also needs to recruit a number of new peer reviewers specifically with an interest in the clinical areas stated above, and also others related to general practice. Peer reviewers are healthcare professionals or epidemiologists with experience in evidence-based medicine. As a peer reviewer you would be asked for your views on the clinical relevance, validity, and accessibility of specific topics within the journal, and their usefulness to the intended audience (international generalists and healthcare professionals, possibly with limited statistical knowledge). Topics are usually 1500-3000 words in length and we would ask you to review between 2-5 topics per year. The peer review process takes place throughout the year, and out turnaround time for each review is ideally 10-14 days. If you are interested in becoming a peer reviewer for Clinical Evidence, please complete the peer review questionnaire at www. clinicalevidence.com/ceweb/contribute/peerreviewer.jsp 